\title{
Neuregulin 1- erbB Signaling Is Necessary for Normal Myelination and Sensory Function
}

\author{
Suzhen Chen, ${ }^{1 \star}$ Miguel Omar Velardez, ${ }^{1 \star}$ Xavier Warot, ${ }^{1}$ Zhao-Xue Yu, ${ }^{1}$ Shyra J. Miller, ${ }^{3}$ Didier Cros, ${ }^{2}$ and \\ Gabriel Corfas ${ }^{1}$ \\ ${ }^{1}$ Division of Neuroscience, Children's Hospital Boston, Harvard Medical School, Boston, Massachusetts 02115, ${ }^{2}$ Department of Neurology, Massachusetts \\ General Hospital and Harvard Medical School, Boston, Massachusetts 02129, and ${ }^{3}$ Department of Pediatrics, University of Cincinnati, Cincinnati Children's \\ Hospital Medical Center, Cincinnati, Ohio 45229-7013
}

To investigate the role of erbB signaling in the interactions between peripheral axons and myelinating Schwann cells, we generated transgenic mice expressing a dominant-negative erbB receptor in these glial cells. Mutant mice have delayed onset of myelination, thinner myelin, shorter internodal length, and smaller axonal caliber in adulthood. Consistent with the morphological defects, transgenic mice also have slower nerve conduction velocity and defects in their responses to mechanical stimulation. Molecular analysis indicates that erbB signaling may contribute to myelin formation by regulating transcription of myelin genes. Analysis of sciatic nerves showed a reduction in the levels of expression of myelin genes in mutant mice. In vitro assays revealed that neuregulin-1 (NRG1) induces expression of myelin protein zero (P0). Furthermore, we found that the effects of NRG1 on P0 expression depend on the NRG1 isoform used. When NRG1 is presented to Schwann cells in the context of cell-cell contact, type III but not type I NRG1 regulates P0 gene expression. These results suggest that disruption of the NRG1-erbB signaling pathway could contribute to the pathogenesis of peripheral neuropathies with hypomyelination and neuropathic pain.

Key words: Schwann cell; myelin protein zero; pain; sciatic nerve; transgenic mouse; neuregulin

\section{Introduction}

Myelin maximizes action potential conduction velocity in vertebrate axons (Waxman, 1997). In peripheral nerves, myelin is a product of Schwann cells. Myelination is a complex process, involving reciprocal neuron-glia interactions. For example, axon signals regulate myelin production (Friede and Samorajski, 1967) and thickness and length of the myelin sheath (Elder et al., 2001), whereas myelin affects axon diameter (Friede and Bischhausen, 1982), formation of the node of Ranvier (Poliak and Peles, 2003), and conduction velocity (Waxman, 1980). Whereas significant progress has been made in understanding the structure of myelinated fibers (Arroyo and Scherer, 2000), the mechanisms that regulate gene expression and morphology in myelinating Schwann cells remain poorly understood.

Neuregulin-1 (NRG1) and the erbB receptors have emerged as key mediators of axon-Schwann cell interactions and regula-

Received Sept. 7, 2005; revised Jan. 4, 2006; accepted Feb. 6, 2006.

This research was supported in part by National Institute of Neurological Disorders and Stroke Grant R01 NS35884 (G.C.) and Mental Retardation Research Center/National Institutes of Health Grant P30-HD 18655 (G.C.). We thank Dr. Clifford Woolf and Michael Greenberg for helpful discussion, Dr. Daniel Broom and Andrew Allchorme for advice on von Frey assay, Dr. Dwanzi Wen for providing type I $\beta$ a NRG1 plasmid, Dr. Michel Revel for pGL3P0-luciferase plasmid, and Dr. Marie Filbin, Dr. Haiying Xia, and Dr. Tom Roberts for providing antibodies. We also thank Pieter Dikkes and Jean Brennan for their histological assistance and Harvard Medical School EM facility for their assistance with EM.

*S.C. and M.O.V. contributed equally to this work.

Correspondence should be addressed to Dr. Gabriel Corfas, Division of Neuroscience, Children's Hospital, 300 Longwood Avenue, Boston, MA 02115. E-mail: gabriel.corfas@childrens.harvard.edu.

DOI:10.1523/JNEUROSCI.3785-05.2006

Copyright $\odot 2006$ Society for Neuroscience $\quad 0270-6474 / 06 / 263079-08 \$ 15.00 / 0$ tors of Schwann cell development. In vitro studies showed that NRG1 induces neural crest cells to adopt the Schwann cell fate (Shah et al., 1994), induces Schwann cell proliferation (Marchionni et al., 1993), promotes the survival of embryonic Schwann cell precursors (Dong et al., 1995) and immature Schwann cells (Syroid et al., 1996), and induces Schwann cell migration (Mahanthappa et al., 1996). In vivo studies showed that NRG1, erbB2, and erbB3 are essential for Schwann cell development (Lee et al., 1995; Meyer and Birchmeier, 1995; Riethmacher et al., 1997). However, these knock-out (KO) mice provided no information about the roles of NRG1-erbB signaling in the postnatal period, the time at which myelination occurs, because of their early lethality. Evidence for the importance of this pathway in myelination came from mice in which the erbB2 expression was eliminated in myelinating Schwann cells by conditional homologous recombination (Garratt et al., 2000) and mice with either one copy of $n r g 1$ gene or overexpressing NRG1 in neurons (Michailov et al., 2004). These studies indicated that NRG1-erbB signaling is essential for generating myelin with normal thickness. However, because most of these analyses were performed in animal models with reductions (hypomorphs) rather than complete elimination of erbB signaling, the contributions of erbB signaling to myelin formation remained poorly defined. Furthermore, the mechanisms by which NRG1-erbB signaling regulates myelin thickness were not explored.

To elucidate the roles of erbB receptor signaling in myelinating Schwann cells, we generated transgenic $(\mathrm{Tg})$ mice that express a dominant-negative erbB receptor (DN-erbB4) under 
the control of the promoter for $2^{\prime}, 3^{\prime}$-cyclic nucleotide $3^{\prime}$ phosphodiesterase (CNPase), an enzyme expressed only in myelinating cells (Scherer et al., 1994; Yin et al., 1997; Gravel et al., 1998). Expression of DN-erbB4 completely blocks erbB2, erbB3, and erbB4 receptor signaling (Rio et al., 1997; Chen et al., 2003; Prevot et al., 2003; Stankovic et al., 2004). Analysis of CNP-DNerbB4 mice shows that erbB signaling in myelinating Schwann cells is necessary for the regulation of both thickness and length of myelin sheaths as well as for the regulation of axonal caliber. In addition, although nerve conduction velocity in adult transgenic mice is severely reduced, these mice display enhanced sensitivity to mechanical stimulation, suggesting that defects in NRG1erbB signaling could be implicated in peripheral neuropathies that involve allodynia/hyperalgesia. To get insights into how erbB signaling regulates myelin structure, we measured the levels of expression of myelin genes and found a reduction in the levels of myelin protein zero (P0), peripheral myelin protein 22 (PMP22), and MBP. Furthermore, in vitro assays revealed that NRG1 induces transcription of the $\mathrm{P} 0$ gene in Schwann cells in an isoformspecific manner. In the context of cell-cell contact, type III but not type I NRG1 increases P0 gene expression. These results demonstrate that NRG1-erbB signaling regulates morphology and gene expression of myelinating Schwann cells during the process of myelination and suggest that defects in this cell-cell contact signaling pathway could underlie the basis of peripheral neuropathies involving pain.

\section{Materials and Methods}

Generation of transgenic mice. A plasmid containing the CNP promoter (Chandross et al., 1999) close to the $5^{\prime}$ end of a multiple cloning site (Ling et al., 2004) was cut with HindIII, blunt ended, and then cut with NotI. Then, the $2.2 \mathrm{~kb}$ NotI-SmaI DN-erbB4 DNA was ligated into the plasmid, and clones were isolated and sequenced. The DNA fragment containing the CNP, promoter, $\mathrm{DN}$-erbB4, and simian virus 40 polyadenylation signal was excised with Ase I and $M l u \mathrm{I}$, gel purified, and used for the generation of transgenic $\mathrm{FVB} / \mathrm{N}$ mice using standard procedures. Animals carrying the transgene were identified by PCR as described previously (Prevot et al., 2003). Two transgenic lines, CNP3 and CNP48, which express high levels of DN-erbB4 in peripheral nerves, were carried to homozygosity and used for additional analysis. The genotypes of homozygous mice were confirmed by analyzing the progeny of presumptive homozygote mice backcrossed to wild-type (WT) mice or by real-time quantitative PCR. The use of animals was approved by the Animal Care and Use Committee of Children's Hospital Boston.

Western blot analysis. Sciatic nerves were dissected and homogenized with a Dounce homogenizer in radioimmunoprecipitation assay buffer (50 mm Tris- $\mathrm{HCl}, \mathrm{pH} 7.4,150 \mathrm{~mm} \mathrm{NaCl}, 1 \mathrm{~mm}$ EDTA, 1\% NP-40, and $0.25 \%$ sodium deoxycholate) containing a mixture of protease inhibitors (Roche, Mannheim, Germany) at $4^{\circ} \mathrm{C}$. Homogenates were centrifuged for $20 \mathrm{~min}$ at $14,000 \mathrm{rpm}$ at $4^{\circ} \mathrm{C}$. Equal amounts of protein from each supernatant (measured with the BCA Protein Assay; Bio-Rad, Hercules, CA) were size fractionated by SDS-PAGE, transferred to nitrocellulose or polyvinylidene difluoride membranes, and immunoblotted. The following antibodies were used: rabbit anti-Flag (1:2000; Santa Cruz Biotechnology, Santa Cruz, CA), rabbit anti-P0 (1:2000; kindly provided by Dr. Marie Filbin, Hunter College, New York, NY), rabbit anti-mouse PMP22 (1:500; kindly provided by Dr. Haiying Xia, Spring Bioscience, Fremont, CA), goat anti-MAG (1:1000; R \& D Systems, Minneapolis, MN), rabbit anti-MBP (1:200; Abcam, Cambridge, MA), mouse anti-glyceraldehyde3-phosphate dehydrogenase (GAPDH) (1:500; Chemicon, Temecula, CA), rabbit anti-NRG1 (1:2000; Santa Cruz Biotechnology), and mouse anti-phosphotyrosine (4G10, 1:5000; kindly provided by Dr. Tom Roberts, Dana-Farber Cancer Institute, Harvard Medical School, Boston, MA). Detection was performed with HRP-conjugated secondary antibodies (1:10,000; Jackson ImmunoResearch, West Grove, PA), followed by the ECL Western blotting detection system (Renaissance; DuPont
NEN, Boston, MA). Signals were detected with a Fujifilm (Tokyo, Japan) Intelligent Dark Box II LAS-3000 plus, followed by quantitation using IP Lab Gel H software. The levels of myelin proteins were normalized using GAPDH signal.

In vivo proliferation and cell death analysis. Cell proliferation was measured by bromodeoxyuridine (BrdU) incorporation assay. Mice were injected intraperitoneally with a BrdU solution in PBS (50 mg/kg BrdU) $4 \mathrm{~h}$ before intracardial perfusion with $4 \%$ paraformaldehyde in PBS. Sciatic nerves were dissected, cryoprotected, cut in $15 \mu \mathrm{m}$ sections, and processed for BrdU immunostaining. Briefly, sections were washed three times in PBS, treated with $2 \mathrm{~N} \mathrm{HCl}$ for $30 \mathrm{~min}$ at $37^{\circ} \mathrm{C}$, washed three times in PBS, and blocked in PBS containing 0.1\% Triton X-100 and $4 \%$ donkey serum. Sections were then incubated with a rat anti-BrdU antibody (1:500; Accurate Chemicals, Westbury, NY) overnight at $4^{\circ} \mathrm{C}$. Sections were then washed with PBS, and detection was performed using the appropriate fluorescent secondary antibodies. Apoptotic cells were detected by using the Fluorescein In Situ Cell Death Detection kit (Roche). Nuclei were counterstained with Hoechst 33342 (Invitrogen, Carlsbad, CA). Data are expressed as percentages of either BrdU-positive or terminal deoxynucleotidyl transferase-mediated biotinylated UTP nick end labeling (TUNEL)-positive nuclei in three cross-sections made through each sciatic nerve from three wild-type and three transgenic mice.

DN-erbB4 immunostaining. Cross-sections, $10 \mu \mathrm{m}$, of paraformaldehyde-fixed sciatic nerves were blocked with 3\% BSA in $0.1 \%$ Triton $\mathrm{X}-100-\mathrm{PBS}$ for $1 \mathrm{~h}$ at room temperature and incubated with mouse anti-erbB4 (H4.77.16, 1:500; NeoMarkers, Fremont, CA) diluted in blocking solution overnight at $4^{\circ} \mathrm{C}$. Sections were washed with PBS, and detection was performed using cyanine 3-conjugated secondary antibodies (1:500; Jackson ImmunoResearch) for $1 \mathrm{~h}$ at room temperature. Images were captured with a confocal microscope (LSM 510 Meta; Zeiss, Oberkochen, Germany).

Morphological analysis of sciatic nerves. Mice were perfused with 2\% paraformaldehyde, $2.5 \%$ glutaraldehyde, and $0.03 \%$ picric acid in $0.1 \mathrm{M}$ cacodylate buffer, $\mathrm{pH}$ 7.2. Tissues were dissected and immersed in the same fixative solution overnight at $4^{\circ} \mathrm{C}$, washed in PBS, osmicated, dehydrated, and embedded in epoxy. One-micrometer-thick sections were stained with toluidine blue. The nerve size was determined by measuring the surface area of cross-sections of sciatic nerves, and the number of myelinated axons was counted by using OpenLab software (Improvision, Conventry, UK). At least three sections through each nerve were used for measurements. Nerve size is presented as the average of the surface area of cross-section. The number of myelinated axons is presented as the average of myelinated axons per cross-section.

Ultrathin sections were subsequently cut, collected on cellodin-coated single-slot grids, stained with uranyl acetate and lead citrate, and photographed with a Jeol (Peabody, MA) 1200EX electron microscope. Micrographs were scanned in a flat-bed scanner and analyzed using MetaMorph (version 6.0; Molecular Devices, Sunnyvale, CA). At least 50 randomly chosen myelinated fibers were analyzed in each sciatic nerve, and, for each one, the axonal and fiber (axon including myelin sheath) areas were measured. Then, $g$ ratio was determined by dividing the axon diameter by the fiber diameter. Three to six sciatic nerves from at least three animals for each genotype were used for the measurement.

Preparation of single nerve fibers and measurement of internode length. Sciatic nerves were removed from perfused mice (see above, Morphological analysis of sciatic nerves). The connective tissue around the nerves was striped off, and the nerves were osmicated with $2 \%$ osmium tetroxide for $6 \mathrm{~h}$ at room temperature, dehydrated with an ethanol series, and then transferred to epoxy. The nerves were separated into single fiber with thin-tipped forceps, which were transferred into a droplet of epoxy on another slide and coverslipped. Images of single fiber were obtained with a Nikon (Tokyo, Japan) microscope (Eclipse E800) using Spot advanced image software (version 3.4.4), and internode length was measured using OpenLab software. At least 40 internode lengths were measured in each nerve. Data represent the average of the lengths of internodes from at least three sciatic nerves of each genotype.

Measurement of tail nerve conduction velocity. Mice were anesthetized by intraperitoneal injection of $40 \mathrm{mg} / \mathrm{kg}$ ketamine and $30 \mathrm{mg} / \mathrm{kg}$ xylazine. Two subcutaneous monopolar needle electrodes (stimulating anode and 
cathode) were positioned at the base of the tail and another two $40 \mathrm{~mm}$ distal to the first pair. A pair of ring recording electrodes was positioned around the tail $20-25 \mathrm{~mm}$ (G1) distal to the distalmost stimulation point and separated by $10 \mathrm{~mm}$ (G1-G2). A portable Synergy Electromyography unit (Oxford Instruments, Old Working, Surrey, UK) was used for stimulation, recording, and data storage. Body temperature was controlled via a rectal probe feeding back into the output to a warming blanket. Additionally, the temperature of the tail was monitored via a thermocouple positioned $30 \mathrm{~mm}$ distal to the base of the tail and maintained to $37^{\circ} \mathrm{C}$ using radiant heat. Supramaximal stimulation was delivered through the proximal and distal pair of stimulating electrodes. Several stimuli were given, and the motor responses were superimposed for consistency. Conduction velocity (meters per second) was calculated by dividing the conduction distance between stimulation sites $(40 \mathrm{~mm})$ into the difference in onset latencies from proximal to distal stimulation sites. Nine animals of each genotype were used for the study.

Sensory testing. Animals were kept in the animal facility with access to food and water ad libitum. Behavioral experiments were always performed at the same time of the day in a quiet environment. To test mechanical sensitivity, animals were placed on an elevated wire grid, and the plantar surface of a hindpaw was stimulated with a series of von Frey hairs (Touch-test Sensory Evaluator kit; Stoelting, Wood Dale, IL). The threshold was taken as the lowest force capable of evoking a brisk withdrawal response in at least 2 of 10 repetitive stimuli to both hind legs. Both the percentage of responsive mice at an indicated force and the average thresholds from wild-type and transgenic mice were analyzed. The hot-plate test was performed using a Controlled Hotplate Analgesia Meter (Columbus Instruments, Columbus, $\mathrm{OH}$ ) heated to $55^{\circ} \mathrm{C}$. Time between start of stimulus and start of foreleg licking or jumping was recorded. Cutoff time of $30 \mathrm{~s}$ was set for the hot-plate test to minimize tissue damage. Nine animals of each genotype were tested in the above tests.

Generation of cell lines expressing isoforms of NRG. HEK-293 cells were transfected with pcDNA3.1 plasmids encoding for either full-length type I $\beta$ a NRG1 (a gift from Dr. Dwanzi Wen, Amgen, Thousand Oaks, CA) or type III $\beta$ a NRG1 cloned from rat embryonic day 15 DRG cDNA. Stably transfected cells were selected with $0.5 \mathrm{mg} / \mathrm{ml} \mathrm{G} 418$. Cell lines were maintained in DMEM with 10\% fetal bovine serum and G418.

Primary Schwann cell culture. Schwann cells were obtained from sciatic nerves of postnatal day 0 (P0) to $\mathrm{P} 2$ rats. Briefly, nerves were dissected from $20-25$ pups and incubated in $1 \%$ collagenase in L-15 medium for $30 \mathrm{~min}$ at $37^{\circ} \mathrm{C}$ and $30 \mathrm{~min}$ more after adding trypsin $(0.25 \%)$. Then, nerves were mechanically dissociated, and cells were plated onto poly-Llysine (PLL)-coated $10 \mathrm{~cm}$ dishes in DMEM with $10 \%$ fetal bovine serum, penicillin/streptomycin, and $2 \mathrm{~mm}$ L-glutamine [Schwann cell medium (SCM)]. Next day, media were changed by fresh SCM containing $10 \mu \mathrm{M}$ cytosine arabinoside. After $3 \mathrm{~d}$, cells were resuspended by trypsinization, incubated with anti-Thyl.1 antibody (Serotec, Raleigh, $\mathrm{NC}$ ) and rabbit complement to eliminate remnant fibroblasts, and replated in fresh SCM. Schwann cells were further maintained in a proliferative state by addition of $1 \mathrm{~nm}$ epidermal growth factor (EGF)-like domain of NRG1 and $5 \mu \mathrm{M}$ forskolin to SCM. For real-time quantitative reverse transcription (RT)-PCR, 80,000 Schwann cells were plated onto PLL-coated 24-well plates in the same medium. After $24 \mathrm{~h}$, medium was changed with fresh SCM without mitogens and maintained for another $24 \mathrm{~h}$, and then treatments were started by addition of DMEM supplemented with B27 alone (control) or with 1 nM EGF-like domain, a suspension of HEK-293 cells, or type I- or type III-expressing HEK-293 cells (50,000 cells per well). After $48 \mathrm{~h}$, total RNA was extracted and subjected to real-time quantitative RT-PCR. For luciferase assay, Schwann cells plated onto PLL-coated 48-well plates were transfected with pGL3P0 plasmid, which contains luciferase under the control of P0 promoter (Slutsky et al., 2003) and TK-renilla plasmid using FUGENE 6 transfection kit (Roche, Indianapolis, IN). After $24 \mathrm{~h}$, Schwann cells were incubated with vehicle or 1 nM EGF-like domain of NRG1 for $48 \mathrm{~h}$. Luciferase assays were performed using the Dual Assay Luciferase kit (Promega, Madison, WI) following the instructions of the manufacturer. For the erbB phosphorylation assay, HEK-293 cells or type I- or type IIIexpressing cells were added to primary cultures of Schwann cells for 20 min. After that, media were aspirated, cells were lysed, and the level of phosphorylation of a band of $185 \mathrm{kDa}$ (p185) was determined by Western blot using an anti-phosphotyrosine antibody (4G10).

Real-time quantitative RT-PCR. Total RNA from primary cultures of Schwann cells was isolated using RNeasy mini kit (Qiagen, Valencia, CA). Real-time quantitative RT-PCR was performed on an iCycler iQ Real-Time Detection System (Bio-Rad) using QuantiTect SYBR Green RT-PCR kit (Qiagen). Expression levels of P0, PMP22, MBP, and MAG in mouse sciatic nerve were determined and normalized as for $18 \mathrm{~S}$. Expression levels of $\mathrm{P} 0$ in cultured rat Schwann cells were normalized as for GAPDH. Standard curves for every set of primers were performed to assess amplification efficiency and dynamic range. Rat-specific primers were used for coculture experiments to specifically amplify Schwann cell cDNA to avoid amplification of cDNA derived from the human cell line. Each sample was measured in quadruplicates. Data were expressed as average of normalized gene expression of at least three independent experiments as described previously (Stankovic and Corfas, 2003). The following forward $(\mathrm{F})$ and reverse $(\mathrm{R})$ primers were used for real-time quantitative RT-PCR: P0, F, 5' -ACCAGACATAGTGGGCAAGACCTC3'; R, 5'-AAGAGCAACAGCAGCAACAGCACC-3'; PMP22, F, 5'GCTCTGTTCCTGTTCTTCTGCCAG-3'; R, 5'-CACTGTGCCTCACTGTGTAGATGG-3'; MBP, F, 5'-ATCCAAGTACCTGGCCACAG-3', R, 5'-CCTGTCACCGCTAAAGAAGC-3', MAG, F, 5' GGAATCAGGAGACATCCCCAAC-3'; R, 5' -TTATCCAAAACAGCGGCAGG-3'; GAPDH, F, 5' -GTGCCAGCCTCGTCTCATAG-3'; R, 5' TGATGGCAACAATGTCCACT-3'，18S，F，5'-CGGCTACCACATCCAAGGAA-3', R, 5' -GCTGGAATTACCGCGGCT-3'.

Statistical analysis. Data are expressed as mean \pm SEM and were evaluated by Student's $t$ test or by one-way ANOVA followed by post hoc tests depending on the experimental design. Axonal diameter distribution was analyzed by $\chi^{2}$ test. Differences among groups were considered significant if $p<0.05$.

\section{Results \\ Disruption of erbB signaling in myelinating Schwann cells in vivo}

To specifically abolish erbB receptor signaling in myelinating Schwann cells, we generated transgenic mice expressing a dominant-negative erbB4 receptor (DN-erbB4) under the control of the promoter for CNPase (Sprinkle, 1989; Gravel et al., 1998; Chandross et al., 1999). DN-erbB4 is a human erbB receptor in which the entire tyrosine kinase domain and all tyrosine phosphorylation sites have been replaced by a Flag epitope tag (Rio et al., 1997). Expression of DN-erbB4 blocks erbB2, erbB3, and erbB4 receptor signaling in all cells tested, including Schwann cells in culture (data not shown), without affecting signaling through other receptors such as the EGF receptor (Rio et al., 1997; Prevot et al., 2003) or Notch (Patten et al., 2003). Several transgenic lines expressing DN-erbB4 were generated, and two expressing high levels of the transgene in peripheral nerves (CNP3 and CNP48) were used for additional experiments.

Western blot analysis showed that DN-erbB4 follows essentially the same time course of expression as CNPase in sciatic nerves (Vogel and Thompson, 1988). The expression of DNerbB4 is undetectable by birth, increases gradually during postnatal development, and reaches the highest levels by postnatal day 21 (P21) (Fig. 1a). By P28, several days after the completion of myelination, immunostaining of transverse sciatic nerve sections with antibodies against the extracellular domain of the human erbB4 showed that DN-erbB4 is expressed specifically by myelinating Schwann cells (Fig. 1b).

\section{Loss of erbB signaling in myelinating Schwann cells results in myelin defects}

Transgenic mice appeared grossly normal for at least the first 24 months after birth. However, by P28, it was evident that sciatic 
a

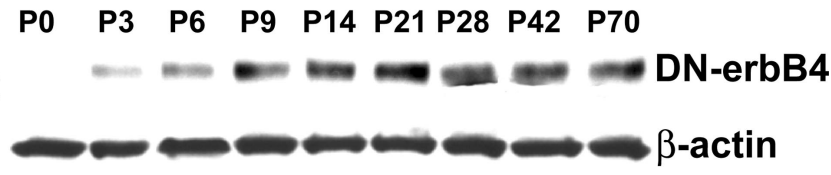

b
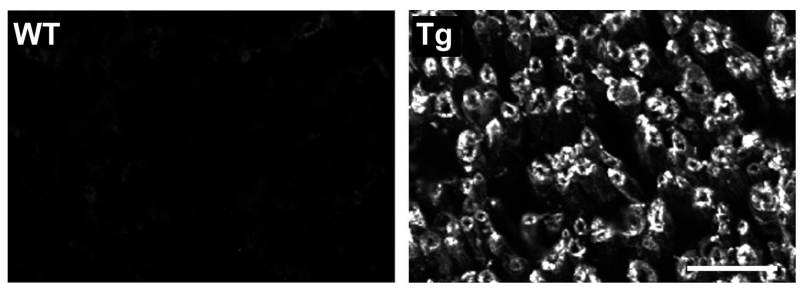

Figure 1. Time course and expression pattern of DN-erbB in the postnatal sciatic nerve. $\boldsymbol{a}$, Western blot analysis of sciatic nerves from CNP-DN-erbB4 mice with anti-Flag antibody shows that DN-erbB4 expression begins after birth and increases gradually, achieving maximal levels by P21. $\beta$-Actin was used as a loading control. $\boldsymbol{b}$, Immunofluorescence staining of sciatic nerve cross-sections from a 4-week-old transgenic mouse with antibodies against erbB4 shows that DN-erbB4 is localized to myelinating Schwann cells. Scale bar, $20 \mu \mathrm{m}$.

nerves of mutants were thinner than those of age-matched wildtype mice ( $p<0.01 ; n=3$ ) (Fig. $2 a, b)$. Because in our previous work in which DN-erbB4 was specifically expressed in nonmyelinating Schwann cells we found nerve thinning along with extensive Schwann cell proliferation and death (Chen et al., 2003), we measured Schwann cell proliferation and death in wild-type and CNP-DN-erbB4 transgenic mice at P28. We found no differences in BrdU incorporation (WT, $3.11 \pm 0.40 \%$; Tg, $4.6 \pm 0.90 \%$; $n=$ 3 ) and TUNEL staining (WT, $1.64 \pm 0.43 \%$; Tg, $1.79 \pm 0.37 \%$; $n=3$ ) between genotypes, indicating that disruption of erbB signaling does not affect the survival or proliferation of adult myelinating Schwann cells.

During the process of peripheral nerve myelination, which occurs between birth and P21, Schwann cells commit to produce myelin sheath by associating with single large-diameter axons. We compared the ultrastructure of transgenic and wild-type sciatic nerves at different times after expression of DN-erbB4 was detectable. As expected, in sciatic nerves of P7 wild-type mice, Schwann cells had already associated with the majority of largecaliber axons, and, in many cases, myelin sheaths became apparent (Fig. $2 c$ ). In contrast, in transgenic mice, although the majority of large-caliber axons showed the 1:1 relationship with Schwann cells, much fewer axons had incipient myelin sheaths (Fig. 2d). Furthermore, the number of myelinated axons in sciatic nerves of transgenic mice was significantly reduced (WT, $1238 \pm$ 156 axons per cross-section; Tg, $684 \pm 284$ axons per cross-section; $p<0.05 ; n=3)$. This indicates that DN-erbB4-expressing Schwann cells are able to associate with axons, but the onset of myelin formation is impaired. At P28, an age at which myelination is normally complete, a strikingly reduced myelin sheath thickness was observed in nerves of transgenic mice (Fig. 2e,f). Quantitative analysis showed that the $g$ ratio was increased by $22 \%$ in sciatic nerves of mutants (WT, $0.680 \pm 0.013$; Tg, $0.827 \pm$ $0.005 ; p<0.001 ; n=3$ ) (Fig. $2 g$ ). This increase in $g$ ratio was seen in both ventral and dorsal roots, demonstrating that the hypomyelination occurs in both motor and sensory axons (data not shown). Furthermore, at P28, the number of myelinated axons in sciatic nerves of transgenic mice was $27 \%$ smaller than in those of wild types (WT, $2023 \pm 140$; Tg, $1483 \pm 149 ; p<0.05 ; n=3$ ), indicating that the disruption of erbB signaling in myelinating Schwann cells leads to failure of a significant number of axons to
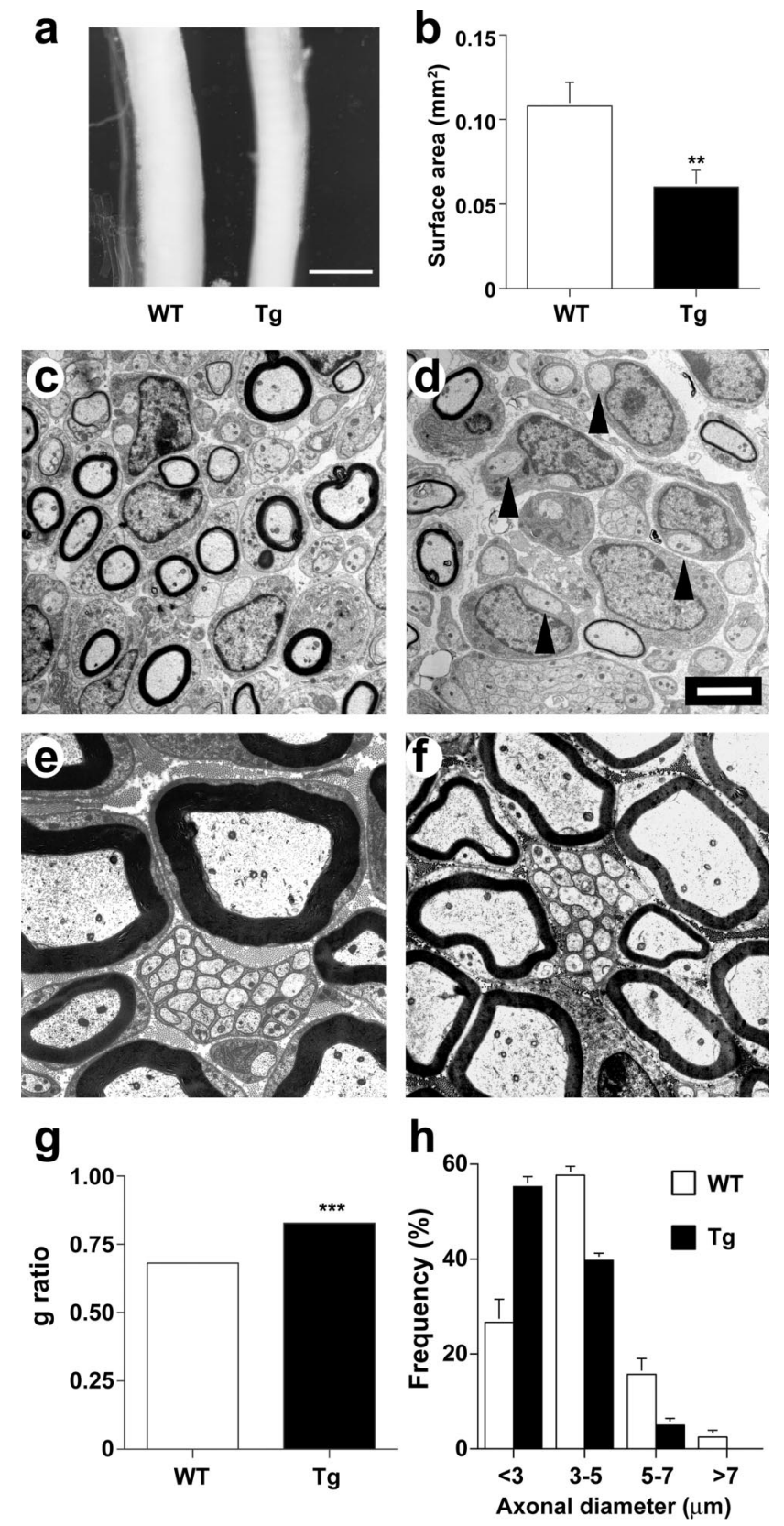

Figure 2. Sciatic nerves of CNP-DN-erbB4 mice are thinner and show alterations in myelin and axonal morphology. $\boldsymbol{a}$, Photomicrograph of freshly dissected sciatic nerves of 4-week-old WT and Tg mice. Scale bar, $370 \mu \mathrm{m}$. $\boldsymbol{b}$, Cross-section surface area of sciatic nerve from 4-weekold transgenic was $45 \%$ thinner than that of wild-type mice $\left({ }^{* *} p<0.01 ; n=3\right) . \boldsymbol{c}$, d, Electron photomicrographs of sciatic nerve cross-sections of P7 wild-type (c) and CNP-DN-erbB4 (d) mice show that, in wild type, most large axons have segregated to form a 1:1 relationship with a Schwann cell and most large-caliber axons have formed significant myelin sheaths (c). In contrast, in the nerves of transgenic mice, most large-caliber axons have not formed myelin sheath (arrowheads), although they have been sorted and associated with Schwann cells (d). Scale bar, $2 \mu \mathrm{m} . \boldsymbol{e}, \boldsymbol{f}$, Electron microphotograph of sciatic nerve cross-sections of P28 wild-type (e) and transgenic $(\boldsymbol{f})$ show that myelin is thinner in the mutant. Scale bar, $1 \mu \mathrm{m} . \boldsymbol{g}, g$ ratio in sciatic nerve fibers of P28 transgenic mice is larger than in wild type $\left({ }^{* * *} p<0.001 ; \boldsymbol{n}=3\right.$ ). $\boldsymbol{h}$, Distribution of axonal caliber in sciatic nerves. The proportion of small-diameter axons $(<3$ $\mu \mathrm{m})$ is increased, whereas that of large-diameter axons $(>5 \mu \mathrm{m})$ is decreased in transgenic mice ( $p<0.001, \chi^{2}$ test).

be myelinated. Importantly, Remak bundles, composed of unmyelinated axons and nonmyelinating Schwann cells, appeared normal (Fig. 2e,f), indicating that NRG1-erbB signaling between unmyelinated axon and nonmyelinating Schwann cells remains 
a

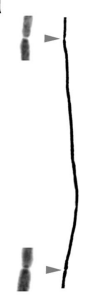

b

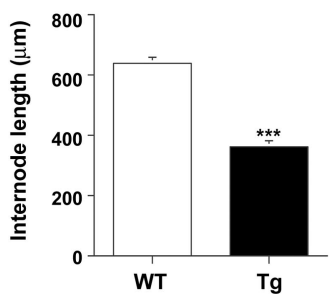

C

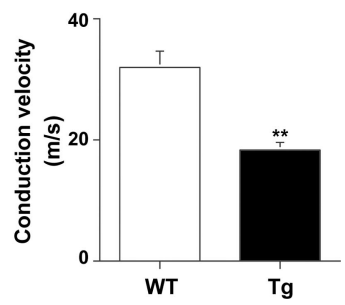

Figure 3. Reduction of internode length and nerve conduction velocity in CNP-DN-erbB4 mice. $\boldsymbol{a}$, Microphotograph of an osmium-stained single sciatic nerve fiber of a 4-week-old mouse. The nodes of Ranvier are indicated by arrows and shown at higher magnification on the left. $\boldsymbol{b}$, Internode length in transgenic mice is shorter than in wild type $\left({ }^{* *} p<0.001 ; n=3\right.$ ). c, Tail nerve conduction velocity in 6-week-old transgenic mice is slower than in wild types $\left({ }^{* *} p<0.01 ; n=9\right)$.

normal. Furthermore, there were no significant differences in the total number of unmyelinated axons between wild-type and transgenic mice (data not shown). However, it is important to note that sciatic nerves contain at least twice as many unmyelinated axons as myelinated ones. Therefore, even if all axons that fail to get myelinated in mutant mice became part of Remak bundles, it would lead to a relatively small increase $(\sim 10 \%)$ in the total number of unmyelinated axons. Given that variation in the number of unmyelinated axons between individual nerves is $>10 \%$, such a change could have gone undetected.

\section{Reduction of axonal caliber, internode length, and nerve conduction velocity in transgenic mice}

A clear correlation between myelin thickness, internode length, and axonal caliber has been demonstrated (Friede and Bischhausen, 1982; Friede and Beuche, 1985; Friede, 1986). We therefore tested whether the alterations of myelin thickness in DN-erbB4-expressing Schwann cells occur in concert with changes in the other two metrics. Analysis of axonal size distribution in P28 nerves showed that the proportion of smalldiameter myelinated axons (smaller than $3 \mu \mathrm{m}$ ) was significantly increased in sciatic nerves of transgenic mice compared with nerves of wild types (WT, $26.65 \pm 4.85 \%$; Tg, $55.26 \pm 2.10 \%$; $p<$ $0.01 ; n=3)$. At the same time, the number of large-diameter myelinated axons $(>5 \mu \mathrm{m})$ in nerves of transgenic mice was decreased (WT, $18.16 \pm 4.78 \%$; Tg, $5.00 \pm 1.40 \% ; p<0.01 ; n=$ 3) (Fig. $2 h$ ). Analysis of single-teased fibers of sciatic nerves from wild-type and mutant mice revealed a $42 \%$ reduction of internode length in transgenic nerves (WT, $638 \pm 34$; Tg, $362 \pm 34$ $\mu \mathrm{m} ; p<0.001 ; n=3$ ) (Fig. $3 a, b$ ). Consistent with the shorter Schwann cells, nerves of adult transgenic mice contained more Schwann cells (405 \pm 38 nuclei per cross-section) than those of wild type ( $257 \pm 13$ nuclei per cross-section) $(p<0.01 ; n=3)$. This likely reflects the fact that more shorter Schwann cells would be needed to cover nerves of normal length.

Myelin sheath thickness and internode length have been shown to correlate with nerve conduction velocity (Waxman, 1980; Friede, 1986; Court et al., 2004). Therefore, we measured conduction velocity of the tail nerve of 6-week-old wild-type and transgenic mice and found that the mean nerve conduction velocity was reduced dramatically in mutant mice (WT, $32.0 \pm 2.7$ $\mathrm{m} / \mathrm{s} ; \mathrm{Tg}, 18.3 \pm 1.3 \mathrm{~m} / \mathrm{s} ; p<0.01 ; n=9$ ) (Fig. $3 c$ ).

Disruption of NRG1-erbB signaling in myelinating Schwann cells leads to hypersensitivity to mechanical stimuli

The morphological and electrophysiological abnormalities of myelinated axons in transgenic mice led us to test the possibility

a

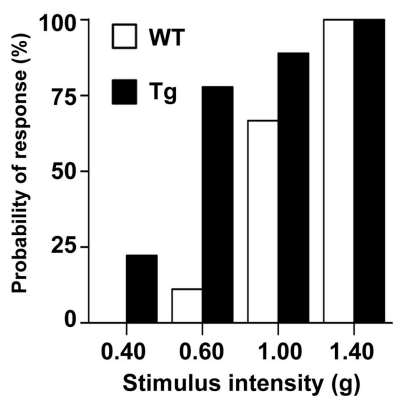

b

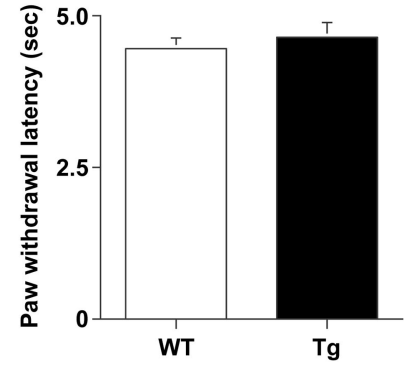

Figure 4. Transgenic mice have hypersensitivity to mechanical stimuli. $\boldsymbol{a}$, Six-week-old mice were tested for mechanosensitivity using calibrated von Frey filaments. Transgenic mice show lower response threshold than wild-type mice. $\boldsymbol{b}$, Transgenic and wild-type mice do not differ in their sensitivity to noxious thermal stimuli as measured by the hot-plate test.

of abnormalities in axon function. We used the von Frey mechanoreception and the hot-plate thermal nociception tests to compare sensory behaviors that are primarily driven by myelinated and unmyelinated axons, respectively. Transgenic mice displayed an increased response to mechanical stimulation (Fig. 4a). Whereas the probability of wild-type mice responding to a stimulus of $0.6 \mathrm{~g}$ of force was small $(11 \%)$, the probability of response of transgenic mice to the same stimulus intensity was $>75 \%$. Furthermore, some transgenic mice $(22 \%)$ even responded to stimuli as little as $0.4 \mathrm{~g}$, which did not elicit responses in wild types. On average, the force required to evoke response from transgenic mice was significantly lower $(0.69 \pm 0.11 \mathrm{~g})$ than from wild-type mice $(1.09 \pm 0.09 \mathrm{~g})(p<0.05 ; n=9)$. In contrast to mechanoreception, thermal nociception was normal in transgenic mice (Fig. 4b), indicating that unmyelinated axons retain normal function in transgenic mice.

\section{Reduction of myelin gene expression in transgenic mice}

Because myelin thickness and length were reduced in these mutant mice, it could be expected that the whole program of myelination would be defective and that the levels of expression of all myelin proteins could be reduced. We measured mRNA levels of P0, PMP22, and MBP in sciatic nerves of wild-type and transgenic mice and found that DN-erbB4 transgenic mice have lower expression of these myelin genes. The reduction in mRNA levels was $38.1 \%$ for P0 ( $p<0.01 ; n=3), 36 \%$ for PMP22 $(p<0.05$; $n=3$ ), and $30.2 \%$ for MBP $(p<0.05 ; n=3$ ) (Fig. $5 a$ ). MAG mRNA was the only myelin gene we tested that was unchanged (data not shown). In agreement with the quantitative PCR results, measurements of levels of myelin proteins in sciatic nerves by semiquantitative Western blot revealed a reduction of $\mathrm{P} 0$ $(63 \% ; p<0.01 ; n=3)$, PMP22 (37\%; $p<0.05 ; n=3)$, and MBP $(17 \% ; p<0.01 ; n=3)$ protein levels in transgenic mice (Fig. $5 b)$. Similar to mRNA measurements, MAG protein levels remained unchanged (data not shown).

\section{P0 gene expression is specifically regulated by type III NRG1} The reduction of myelin gene expression in sciatic nerves of DNerbB4 transgenic mice prompted us to investigate whether NRG1-erbB signaling directly regulates the expression of myelin genes in Schwann cells in culture. We focused this analysis on P0 because it is the major myelin protein of peripheral nervous system, because it has been shown that P0 expression is actively regulated by the presence of axons (Lee et al., 1997), and because $\mathrm{P} 0$ was the myelin protein most strongly downregulated in $\mathrm{DN}$ - 
erbB4 mice. Stimulation of Schwann cells in culture with soluble EGF-like domain of NRG1 for 48 h resulted in a twofold increase in P0 mRNA levels ( $p<0.01 ; n=$ 9) (Fig. $6 a$, left). P0 mRNA levels appeared to be regulated at the transcriptional level because we observed a similar increase in P0 promoter activity by using a luciferase assay $(p<0.01 ; n=9)$ (Fig. $6 a$, right).

Whereas the soluble EGF-like domain of NRG1 is commonly used for in vitro studies, in vivo NRG1 is expressed mostly as a transmembrane protein that contains other domains beyond the EGF-like domain (Buonanno and Fischbach, 2001; Falls, 2003). Furthermore, alternative splicing of the NRG1 gene generates several different isoforms, which differ in these additional domains (Buonanno and Fischbach, 2001; Falls, 2003). Type I and type II NRG1 contain an Ig-like domain, whereas type III NRG1 contains a cysteine-rich domain (CRD). To test whether the isoforms differ in their ability to regulate myelin gene expression, we generated HEK-293 cell lines stably expressing either type I $\beta$ a or type III $\beta$ a fulllength NRG1 (Falls, 2003). Western blot analysis of cell lysates showed that both cell lines expressed NRG1 of the expected molecular weights (Fig. 6b, top). Two lines of evidence showed that NRG1 isoforms were inserted into the cell membrane in the right orientation. First, immunostaining with antibodies directed against the intracellular domain of NRG1 labeled cells only after permeabilization (data not shown). Second, addition of a suspension of the NRG1-expressing HEK-293 cells to Schwann cells resulted in rapid erbB phosphorylation in the glial cells (Fig. 6b, bottom).

We then tested whether the different NRG1 isoforms have different effects on the expression of P0. Schwann cells were cocultured for $48 \mathrm{~h}$ with the different cell lines, and mRNA levels of these genes were measured by real-time quantitative RT-PCR with primers that amplify murine but not human transcripts. As shown in Figure $6 c$, only the contact with type III NRG1-expressing cells increased P0 mRNA levels in Schwann cells $(p<0.05 ; n=6)$.

\section{Discussion}

The results described above show that erbB signaling in myelinating Schwann cells is necessary for the normal progression of myelination and provide insights into the mechanisms by which this occurs. erbB2 and erbB3 receptors are expressed at all of the stages of Schwann cell development, from neural crest cells to fully differentiated Schwann cells, and their function is critical for their development (Corfas et al., 2004). Similarly, the CNPase promoter has been shown to drive transgene expression at all stages of Schwann cell development (Chandross et al., 1999). However, CNPase promoter activity is very weak before birth and b

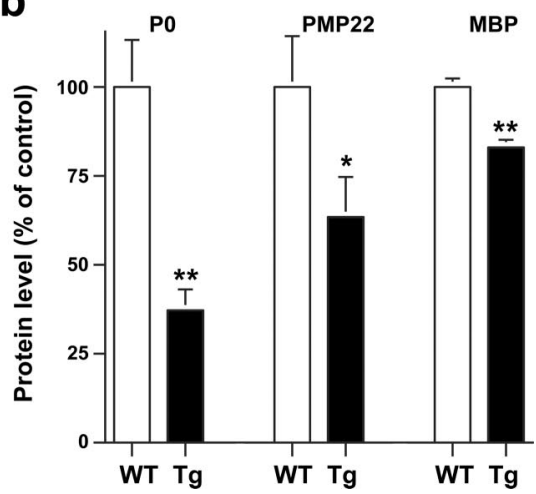

Figure 5. Reduction in the level of expression of myelin genes in sciatic nerves of transgenic mice. $\boldsymbol{a}$, The levels of P0, PMP22, $\boldsymbol{b}$, Semiquantitative Western blot analysis of P0, PMP22, and MBP expression, using GAPDH as a normalizer, shows that the levels

a

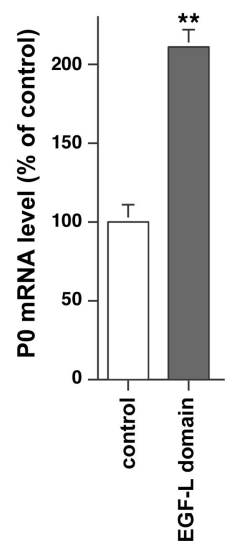

Figure 6. NRG1 isoform-specific effects on P0 expression in Schwann cells in vitro. $\boldsymbol{a}$, Schwann cells in culture were either left treatment with the EGF-like domain of NRG1 $\left.{ }^{* *} p<0.01 ; n=9\right)$. $\boldsymbol{b}$, Top, Western blot analysis of HEK-293 cell lines stably expressing either type I or type III NRG1 with antibodies against the intracellular domain of NRG1 shows bands of the expected lines for 20 min shows that both NRG1-expressing lines induce erbB receptor phosphorylation (p185) in Schwann cells, whereas the control cells do not. c, PO mRNA in Schwann cells is increased fourfold by coculture with HEK-293 cells expressing type III NRG1, but contact with cells expressing type I NRG1 has no effect $\left({ }^{*} p<0.05 ; n=6\right)$.

becomes intense only in the postnatal period, peaking $\sim 2-3$ weeks after birth. This is in agreement with DN-erbB4 being detected in sciatic nerves only by P3 and peaking at P21. These observations provide an explanation for the postnatal nature of the phenotypes observed in CNP-DN-erbB4 mice.

The hypomyelination resulting from the elimination of erbB signaling by DN-erbB4 expression in myelinating Schwann cells is very similar to that described in mice in which erbB2 expression was specifically eliminated in these glial cells by conditional $\mathrm{KO}$ technique (Garratt et al., 2000) and in mice with only one copy of the nrg1 gene (Michailov et al., 2004). These results, together with the observation that overexpression of NRG1 in neurons results in increased myelin thickness (Michailov et al., 2004), indicate that NRG1-erbB signaling is essential for normal myelination. Importantly, whereas the reduction in the levels of NRG1 expression was found to alter myelin thickness but not internode length and axonal caliber (Michailov et al., 2004), our mice in which 
erbB signaling is completely eliminated by DN-erbB4 show alterations in all of these parameters. Therefore, we conclude that erbB signaling is necessary for the elaboration of both normal myelin thickness and length as well as the ability of myelinating Schwann cells to control axonal caliber, and that the absence of internode length and axonal caliber defects in the study by Michailov et al. (2004) was probably attributable to the fact that they studied hypomorphs rather than null phenotypes.

Our results also indicate that erbB signaling does not regulate either cell proliferation or survival of myelinating Schwann cells. Although the sciatic nerve of CNP-DN-erbB4 mice contains more Schwann cells than wild type, this appears to reflect a compensation for the shorter internode length, i.e., a larger number of myelinating Schwann cells are necessary to cover the whole length of myelinated axons when the myelin sheaths are shorter. Thus, the roles of erbB signaling in the myelinating Schwann cells are very different from those it plays in Schwann cell precursors, in which it promotes cell proliferation and survival (Dong et al., 1995; Syroid et al., 1996), or in adult nonmyelinating Schwann cells, in which it inhibits proliferation but promotes their survival and morphological stability (Chen et al., 2003). Hence, signaling through erbB2 and erbB3, the two family members expressed by all Schwann cells, elicits remarkably different biological effects depending on the developmental stage of the cell or the phenotype a Schwann cell may have adopted.

In CNP-DN-erbB4 mice, the expression of several myelin proteins was reduced, showing that production of normal levels of those proteins depends on erbB signaling. Interestingly, MAG mRNA and protein levels were unchanged in transgenic mice, suggesting that the regulation of this gene is independent of erbB signaling and different from the other myelin genes analyzed. The MAG promoter has neither canonical TATA box nor initiator motifs (Konat, 1996). Moreover, MAG gene activation involves profound demethylation of two CpG dinucleotides upstream of the promoter core (Konat, 1996). These unique characteristics of the MAG promoter may be the reason why this gene was not affected in CNP-DN-erbB4 mice. We were unable to test whether NRG1 regulates MAG expression in Schwann cells in culture because MAG mRNA was undetectable under our experimental conditions.

The ways in which erbB signaling affects Schwann cells appear to depend not only on the stage of development but also on the specific isoform of the ligand that binds the receptors. erbB receptor activation by the EGF-like domain of NRG1 is sufficient to induce P0 expression by Schwann cells in culture, the presence of the CRD (type III NRG1) results in an even greater induction, whereas inclusion of the Ig-like domain (type I NRG1) completely eliminates this effect. Interestingly, a recent study by Taveggia et al. (2005) also provided evidence that type III NRG1 is the one that promotes myelination in vitro. These results suggest that the Ig-like and CRD domains of NRG1 have important modulatory effects on the functional core of this factor, the EGFlike domain, their presence or absence changing the downstream effects of the erbB signaling. This raises the possibility that the Ig-like and CRD domains change the way in which NRG1 interacts and activates erbB receptors or that they help recruit other membrane proteins to the erbB receptor complex, which could alter the ways in which the receptors signal.

The specific alterations in sensory responses, i.e., transgenic mice having defects in the mechanosensory modality but not in thermal nociception, together with the fact that Remak bundle structure is preserved in CNP-DN-erbB4 mice provide evidence for the specificity of expression of DN-erbB4 to myelinating
Schwann cells. Therefore, this hypersensitivity is most likely attributable to alterations of the myelinated fibers, which have been shown to mediate $>90 \%$ of withdrawal reactions to light-touch stimulation (Shir and Seltzer, 1990) and the mechanical hypersensitivity observed in tactile allodynia (Koltzenburg, 1998; Woolf et al., 1998). Thus, our results suggest that reductions in NRG1-erbB signaling may be involved in pathogenesis of peripheral neuropathies with hypomyelination and neuropathic pain. Pain and excessive sensitivity in human peripheral demyelinating and degenerative diseases are usually associated with damage of sensory nerves (Pentland and Donald, 1994; Woolf, 2004). Our results indicate that changes in cytoarchitecture of myelinating Schwann cells could be responsible for hyperalgesic or allodynic states and spontaneous pain observed in peripheral neuropathies such as Charcot-Marie-Tooth disease type 1 and type 4 (Carter et al., 1998; Guilbot et al., 2001; Takashima et al., 2002), Guillain-Barre syndrome (Moulin, 1998), and after nerve injury (Schaible and Richter, 2004). However, it should be noted that hypomyelination does not always result in neuropathic pain. Such is the case of mice heterozygous for the P0 gene, which have demyelination and decreased conduction velocity but, in contrast to the CNP-DN-erbB4 mice, have reduced rather than increased responses to mechanical stimuli (Samsam et al., 2002). The mechanisms underlying neuropathic pain are not precisely determined yet (Woolf, 2004), but the deregulation of voltagegated sodium channel expression certainly can contribute to the etiology of this condition (Black et al., 2004; Hains et al., 2004). erbB2 has been shown to be highly localized in Schwann cell microvilli (Guertin et al., 2005) in which they appear as a compact halo surrounding voltage-gated sodium channels at the nodes of Ranvier (Yang et al., 2004). Thus, alterations in erbB signaling at nodes of Ranvier may result in changes in sodium channel expression, localization, or function, which could contribute to the sensory phenotype.

\section{References}

Arroyo EJ, Scherer SS (2000) On the molecular architecture of myelinated fibers. Histochem Cell Biol 113:1-18.

Black JA, Liu S, Tanaka M, Cummins TR, Waxman SG (2004) Changes in the expression of tetrodotoxin-sensitive sodium channels within dorsal root ganglia neurons in inflammatory pain. Pain 108:237-247.

Buonanno A, Fischbach GD (2001) Neuregulin and ErbB receptor signaling pathways in the nervous system. Curr Opin Neurobiol 11:287-296.

Carter GT, Jensen MP, Galer BS, Kraft GH, Crabtree LD, Beardsley RM, Abresch RT, Bird TD (1998) Neuropathic pain in Charcot-Marie-Tooth disease. Arch Phys Med Rehabil 79:1560-1564.

Chandross KJ, Cohen RI, Paras Jr P, Gravel M, Braun PE, Hudson LD (1999) Identification and characterization of early glial progenitors using a transgenic selection strategy. J Neurosci 19:759-774.

Chen S, Rio C, Ji RR, Dikkes P, Coggeshall RE, Woolf CJ, Corfas G (2003) Disruption of ErbB receptor signaling in adult non-myelinating Schwann cells causes progressive sensory loss. Nat Neurosci 6:1186-1193.

Corfas G, Velardez MO, Ko CP, Ratner N, Peles E (2004) Mechanisms and roles of axon-Schwann cell interactions. J Neurosci 24:9250-9260.

Court FA, Sherman DL, Pratt T, Garry EM, Ribchester RR, Cottrell DF, Fleetwood-Walker SM, Brophy PJ (2004) Restricted growth of Schwann cells lacking Cajal bands slows conduction in myelinated nerves. Nature 431:191-195.

Dong Z, Brennan A, Liu N, Yarden Y, Lefkowitz G, Mirsky R, Jessen KR (1995) Neu differentiation factor is a neuron-glia signal and regulates survival, proliferation, and maturation of rat Schwann cell precursors. Neuron 15:585-596.

Elder GA, Friedrich Jr VL, Lazzarini RA (2001) Schwann cells and oligodendrocytes read distinct signals in establishing myelin sheath thickness. J Neurosci Res 65:493-499.

Falls DL (2003) Neuregulins: functions, forms, and signaling strategies. Exp Cell Res 284:14-30. 
Friede RL (1986) Relation between myelin sheath thickness, internode geometry, and sheath resistance. Exp Neurol 92:234-247.

Friede RL, Beuche W (1985) A new approach toward analyzing peripheral nerve fiber populations. I. Variance in sheath thickness corresponds to different geometric proportions of the internodes. J Neuropathol Exp Neurol 44:60-72.

Friede RL, Bischhausen R (1982) How are sheath dimensions affected by axon caliber and internode length? Brain Res 235:335-350.

Friede RL, Samorajski T (1967) Relation between the number of myelin lamellae and axon circumference in fibers of vagus and sciatic nerves of mice. J Comp Neurol 130:223-231.

Garratt AN, Voiculescu O, Topilko P, Charnay P, Birchmeier C (2000) A dual role of erbB2 in myelination and in expansion of the Schwann cell precursor pool. J Cell Biol 148:1035-1046.

Gravel M, Di Polo A, Valera PB, Braun PE (1998) Four-kilobase sequence of the mouse CNP gene directs spatial and temporal expression of lacZ in transgenic mice. J Neurosci Res 53:393-404.

Guertin AD, Zhang DP, Mak KS, Alberta JA, Kim HA (2005) Microanatomy of axon/glial signaling during Wallerian degeneration. J Neurosci 25:3478-3487.

Guilbot A, Williams A, Ravise N, Verny C, Brice A, Sherman DL, Brophy PJ, LeGuern E, Delague V, Bareil C, Megarbane A, Claustres M (2001) A mutation in periaxin is responsible for $\mathrm{CMT} 4 \mathrm{~F}$, an autosomal recessive form of Charcot-Marie-Tooth disease. Hum Mol Genet 10:415-421.

Hains BC, Saab CY, Klein JP, Craner MJ, Waxman SG (2004) Altered sodium channel expression in second-order spinal sensory neurons contributes to pain after peripheral nerve injury. J Neurosci 24:4832-4839.

Koltzenburg M (1998) Painful neuropathies. Curr Opin Neurol 11:515-521.

Konat GW (1996) Chromatin structure and transcriptional activity of MAG gene. Acta Neurobiol Exp (Wars) 56:281-285.

Lee KF, Simon H, Chen H, Bates B, Hung MC, Hauser C (1995) Requirement for neuregulin receptor erbB2 in neural and cardiac development. Nature 378:394-398.

Lee M, Brennan A, Blanchard A, Zoidl G, Dong Z, Tabernero A, Zoidl C, Dent MA, Jessen KR, Mirsky R (1997) P0 is constitutively expressed in the rat neural crest and embryonic nerves and is negatively and positively regulated by axons to generate non-myelin-forming and myelin-forming Schwann cells, respectively. Mol Cell Neurosci 8:336-350.

Ling B, Wu J, Miller SJ, Rizvi TA, Monk KR, Shamekh R, Hadley J, Vogel K, DeClue JE, Ratner N (2004) Role for the epidermal growth factor receptor in neurofibromatosis-related peripheral nerve tumorigenesis. Cancer Cell 7:65-75.

Mahanthappa NK, Anton ES, Matthew WD (1996) Glial growth factor 2, a soluble neuregulin, directly increases Schwann cell motility and indirectly promotes neurite outgrowth. J Neurosci 16:4673-4683.

Marchionni MA, Goodearl AD, Chen MS, Bermingham-McDonogh O, Kirk C, Hendricks M, Danehy F, Misumi D, Sudhalter J, Kobayashi K, Wroblewski D, Lynch C, Baldassare M, Hiles I, Davis JB, Hsuan JJ, Totty NF, Otsu M, McBurney RN, Waterfield MD, et al. (1993) Glial growth factors are alternatively spliced erbB2 ligands expressed in the nervous system. Nature 362:312-318.

Meyer D, Birchmeier C (1995) Multiple essential functions of neuregulin in development. Nature 378:386-390.

Michailov GV, Sereda MW, Brinkmann BG, Fischer TM, Haug B, Birchmeier C, Role L, Lai C, Schwab MH, Nave KA (2004) Axonal neuregulin-1 regulates myelin sheath thickness. Science 304:700-703.

Moulin DE (1998) Pain in central and peripheral demyelinating disorders. Neurol Clin 16:889-898.

Patten BA, Peyrin JM, Weinmaster G, Corfas G (2003) Sequential signaling through Notch1 and erbB receptors mediates radial glia differentiation. J Neurosci 23:6132-6140.

Pentland B, Donald SM (1994) Pain in the Guillain-Barre syndrome: a clinical review. Pain 59:159-164.

Poliak S, Peles E (2003) The local differentiation of myelinated axons at nodes of Ranvier. Nat Rev Neurosci 4:968-980.
Prevot V, Rio C, Cho GJ, Lomniczi A, Heger S, Neville CM, Rosenthal NA, Ojeda SR, Corfas G (2003) Normal female sexual development requires neuregulin-erbB receptor signaling in hypothalamic astrocytes. J Neurosci 23:230-239.

Riethmacher D, Sonnenberg-Riethmacher E, Brinkmann V, Yamaai T, Lewin GR, Birchmeier C (1997) Severe neuropathies in mice with targeted mutations in the ErbB3 receptor. Nature 389:725-730.

Rio C, Rieff HI, Qi P, Khurana TS, Corfas G (1997) Neuregulin and erbB receptors play a critical role in neuronal migration. Neuron 19:39-50.

Samsam M, Frei R, Marziniak M, Martini R, Sommer C (2002) Impaired sensory function in heterozygous $\mathrm{P} 0$ knockout mice is associated with nodal changes in sensory nerves. J Neurosci Res 67:167-173.

Schaible HG, Richter F (2004) Pathophysiology of pain. Langenbecks Arch Surg 389:237-243.

Scherer SS, Braun PE, Grinspan J, Collarini E, Wang DY, Kamholz J (1994) Differential regulation of the $2^{\prime}, 3^{\prime}$-cyclic nucleotide $3^{\prime}$ phosphodiesterase gene during oligodendrocyte development. Neuron 12:1363-1375.

Shah NM, Marchionni MA, Isaacs I, Stroobant P, Anderson DJ (1994) Glial growth factor restricts mammalian neural crest stem cells to a glial fate. Cell 77:349-360.

Shir Y, Seltzer Z (1990) A-fibers mediate mechanical hyperesthesia and allodynia and C-fibers mediate thermal hyperalgesia in a new model of causalgiform pain disorders in rats. Neurosci Lett 115:62-67.

Slutsky SG, Kamaraju AK, Levy AM, Chebath J, Revel M (2003) Activation of myelin genes during transdifferentiation from melanoma to glial cell phenotype. J Biol Chem 278:8960-8968.

Sprinkle TJ (1989) 2',3'-cyclic nucleotide 3'-phosphodiesterase, an oligodendrocyte-Schwann cell and myelin-associated enzyme of the nervous system. Crit Rev Neurobiol 4:235-301.

Stankovic KM, Corfas G (2003) Real-time quantitative RT-PCR for lowabundance transcripts in the inner ear: analysis of neurotrophic factor expression. Hear Res 185:97-108.

Stankovic K, Rio C, Xia A, Sugawara M, Adams JC, Liberman MC, Corfas G (2004) Survival of adult spiral ganglion neurons requires erbB receptor signaling in the inner ear. J Neurosci 24:8651-8661.

Syroid DE, Maycox PR, Burrola PG, Liu N, Wen D, Lee KF, Lemke G, Kilpatrick TJ (1996) Cell death in the Schwann cell lineage and its regulation by neuregulin. Proc Natl Acad Sci USA 93:9229-9234.

Takashima H, Boerkoel CF, De Jonghe P, Ceuterick C, Martin JJ, Voit T, Schroder JM, Williams A, Brophy PJ, Timmerman V, Lupski JR (2002) Periaxin mutations cause a broad spectrum of demyelinating neuropathies. Ann Neurol 51:709-715.

Taveggia C, Zanazzi G, Petrylak A, Yano H, Rosenbluth J, Einheber S, Xu X, Esper RM, Loeb JA, Shrager P, Chao MV, Falls DL, Role L, Salzer JL (2005) Neuregulin-1 type III determines the ensheathment fate of axons. Neuron 47:681-694.

Vogel US, Thompson RJ (1988) Molecular structure, localization, and possible functions of the myelin-associated enzyme $2^{\prime}, 3^{\prime}$-cyclic nucleotide $3^{\prime}$-phosphodiesterase. J Neurochem 50:1667-1677.

Waxman SG (1980) Determinants of conduction velocity in myelinated nerve fibers. Muscle Nerve 3:141-150.

Waxman SG (1997) Axon-glia interactions: building a smart nerve fiber. Curr Biol 7:R406-R410.

Woolf CJ (2004) Dissecting out mechanisms responsible for peripheral neuropathic pain: implications for diagnosis and therapy. Life Sci 74:2605-2610.

Woolf CJ, Bennett GJ, Doherty M, Dubner R, Kidd B, Koltzenburg M, Lipton R, Loeser JD, Payne R, Torebjork E (1998) Towards a mechanism-based classification of pain? Pain 77:227-229.

Yang Y, Lacas-Gervais S, Morest DK, Solimena M, Rasband MN (2004) $\beta I V$ spectrins are essential for membrane stability and the molecular organization of nodes of Ranvier. J Neurosci 24:7230-7240.

Yin X, Peterson J, Gravel M, Braun PE, Trapp BD (1997) CNP overexpression induces aberrant oligodendrocyte membranes and inhibits MBP accumulation and myelin compaction. J Neurosci Res 50:238-247. 